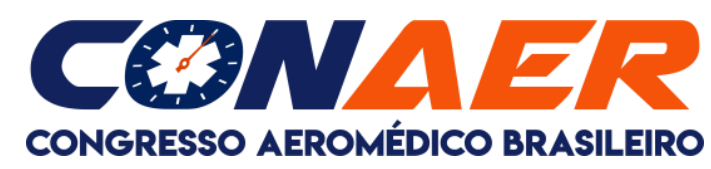

\title{
ANÁLISE ESTATÍSTICA DO SERVIÇO AEROMÉDICO UNIFICADO DO DISTRITO FEDERAL
}

Mônica Beatriz Ortolan LIBARDI ${ }^{1}$; Adrielle de Sousa OVIDES ${ }^{2}$; Yara Stephany da SILVA.

\section{RESUMO}

Introdução: o Serviço Unificado de Atendimento Pré-Hospitalar (SUAPH) por meio do Serviço de Atendimento Móvel de Urgência do Distrito Federal (SAMU DF) e do Corpo de Bombeiro Militar do Distrito Federal (CBMDF) prestam conjuntamente à população do Distrito Federal (DF) o serviço de Atendimento Pré-Hospitalar (APH) inclusive do Serviço Aeromédico (SA), destinado à vítima que necessita de temporesposta breve devido à gravidade, com suporte avançado de vida e tratamento definitivo nos hospitais de referência. Justificativa: Brasília passou a contar com o SA SAMU DF em parceria com CBMDF em 2009, vigente até hoje, complementado com a portaria de consolidação e conjunta de 2018. Organizado por uma equipe de operadores médicos, aerotáticos, entre outros, propõe união da equipe, o que é diferencial nos procedimentos. Objetivo: apresentar resultados quantitativos estatísticos dessa parceria, para futuro parâmetro ao planejamento estratégico à capacitação profissional. Método: estudo descritivo-analítico, retrospectivo com busca ativa dos registros em fichas de ocorrências realizadas no período de 2019 e 2020. Resultados e conclusões: o SA ofertou 1023 atendimentos às urgências no $\mathrm{APH}$, na maior proporção ao sexo masculino, sendo a parada cardiorrespiratória (PCR) prevalente. Destas, 325 foram a óbitos por PCR e 100 apresentaram Retorno da Circulação Espontânea (RCE) após reanimação cardiopulmonar (RCP) com equipe do SA no local da cena até o transporte à unidade de saúde. Reflexões sobre a integração multiprofissional e interinstitucional, através dos dados estatísticos produzidos, concernem para a capacitação no SA em APH no DF.

Palavras-chave: Estatística, serviço aeromédico, Distrito Federal.

\section{INTRODUÇÃO}

A Secretaria de Estado de Saúde do Distrito Federal por meio do Serviço de Atendimento Móvel de Urgência (SAMU) e do Corpo de Bombeiro Militar do Distrito Federal (CBMDF) prestam à população do Distrito Federal (DF) o serviço de Atendimento Pré-Hospitalar (APH).

Com a intenção de aperfeiçoar a prestação de serviço de APH à comunidade do DF foi instituído o Serviço Unificado de Atendimento Pré-Hospitalar (SUAPH) com a integração de todos os processos do serviço, inclusive o de Serviço Aeromédico $(\mathrm{SA})$, destinado à vítima que necessita de tempo-resposta breve devido à gravidade, ${ }^{1}$ Enfermeira. Mestre em Ciências da Saúde, Serviço de Atendimento Móvel de Urgência do Distrito Federal.

E-mail: monicab.libardi@gmail.com

${ }^{2}$ Acadêmica. $8^{\circ}$ Semestre de Enfermagem Centro Universitário do Distrito Federal.

E-mail: adrielle.ovides@outlook.com

${ }^{3}$ Acadêmica. $5^{\circ}$ Semestre de Enfermagem Escola Superior de Ciências da Saúde.

E-mail: yara.stephany99@gmail.com 
com suporte avançado de vida e tratamento definitivo nos hospitais de referência, com regulação médica (BRASIL, 2018).

O SA em parceria está vigente desde 2009 e atua até hoje, complementado com a portaria de consolidação e conjunta com repasse ministerial em 2018 (PEDREZANI, 2020).

Apresentar a experiência da implantação do SUAPH e os resultados quantitativos e estatísticos dessa parceria no SA poderá servir de parâmetro para futuro planejamento estratégico em educação à equipe do $S A$, além de oportunizar a difusão do serviço tal como ofertado nesse período de 24 meses entre 2019 e 2020 no DF.

\section{METODOLOGIA}

Estudo descritivo-analítico, retrospectivo na temática do SA no DF, com busca ativa dos registros em fichas de ocorrências do CBMDF e SAMU DF, no recorte temporal de 2019 e 2020, totalizando 24 meses.

\section{RESULTADOS E DISCUSSÕES}

A atual pesquisa relata 1023 ocorrências nos 24 meses, com maior número absoluto no mês de julho de 2019 (59 ocorrências), mesmo mês de prevalência em estudo do Reino Unido, com 126 casos (BENI, 2020), e Nardoto; Diniz \& Cunha (2011), com 23 casos.

Das urgências diagnosticadas na cena em atual pesquisa, houve maior quantitativo de atendimentos de Parada Cardiorrespiratória (PCR) nos 24 meses com 425 ocorrências de um total de 1023 (41,54\%), seguida de acidentes automobilísticos, afogamentos, quedas de altura, projéteis de arma de fogo (PAF), perfurações por arma branca (PAB), entre outros.

Em estudo no sudoeste da Inglaterra o maior quantitativo das ocorrências culminou em emergências cardíacas, seguidas de acidente vascular cerebral (AVC), problemas respiratórios, acidentes de trânsito e quedas (BENI, 2020), e para Nascimento et al., (2018) queda de nível, permanecendo PCR com menor quantitativo.

A menor idade dos atendimentos no levantamento atual foi de três dias de vida em contrapartida com a maior de 101 anos. A média das 10 primeiras idades foi 50,4 anos. Nardoto; Diniz \& Cunha (2011) registraram maior frequência aos 34 anos, em Kreusch (2018) predominou a faixa etária dos 20 a 29 anos e em Nascimento et al (2018) entre 60-64 anos. 
No atual relato, o sexo masculino predominou nos atendimentos com 669 ocorrências, em contrapartida ao feminino com 298, assim como relato de Kreusch (2018), Nardoto; Diniz \& Cunha (2011) e Nascimento et al (2018).

O turno vespertino foi o de maior frequência de acionamentos, seguido do matutino, do noturno e da madrugada. Kreusch (2018) também encontrou o vespertino como período prevalente.

O tempo médio de deslocamento da aeronave, no atual relato, até o local da cena foi de 16 minutos e 56 segundos. Nardoto; Diniz \& Cunha (2011) relataram 11 minutos, o mesmo na Inglaterra (BENI, 2020). Bitencourt et al (2021) salienta que a construção de helipontos em centros de trauma pode reduzir o tempo de transporte, os custos e as sequelas do trauma, que fazem parte da atual estatística relatada.

Após o atendimento da vítima por equipe do SA, houve deslocamento à regional de saúde em asa rotativa em $66,33 \%$ dos acionamentos e 33,66\% por terra, em viatura de Unidade de Resgate, Unidade de Suporte Básico ou Avançado.

Quanto à Escala de Coma de Glasgow (ECG) no atual relato, 430 ocorrências apresentam escore 3, computadas 140 com valor 15 e 23 com pontuação 14, entre outros de menor quantitativo. Segundo Kreusch (2018), de 190 atendidos, 23,1\% apresentaram ECG 3-8; e segundo Maia (2015), 36,5\% têm escore entre 13-15, seguido de $26,2 \%$ entre $3-8$.

O atual estudo verificou que, antes da chegada do SA no local, foi ofertada reanimação cardiopulmonar $(\mathrm{RCP})$ por outra equipe $\mathrm{APH}$ por alguns minutos, atitude valorosa no Suporte Básico de Vida (SBV) proposto pela diretriz da American Heart Association ao APH, como mostra a Tabela 1(AHA, 2020). Já a Tabela 2, revela o tempo de RCP com o SA na cena.

Tabela 1 - RCP Antes da chegada do SA.

\begin{tabular}{|c|c|}
\hline $\begin{array}{c}\text { RCP em MINUTOS antes } \\
\text { do SA }\end{array}$ & № ocorrências \\
\hline
\end{tabular}

\begin{tabular}{|l|l|}
\hline $20 \mathrm{~min}$ & 46 \\
\hline $30 \mathrm{~min}$ & 37 \\
\hline $40 \mathrm{~min}$ & 18 \\
\hline $15 \mathrm{~min}$ & 15 \\
\hline $25 \mathrm{~min}$ & 13 \\
\hline $35 \mathrm{~min}$ & 12 \\
\hline
\end{tabular}

Tabela 2 - RCP depois da chegada do SA.

\begin{tabular}{|l|l|}
\hline $\begin{array}{l}\text { RCP em MINUTOS com o } \\
\text { SA }\end{array}$ & № ocor \\
\hline $20 \mathrm{~min}$ & 34 \\
\hline $50 \mathrm{~min}$ & 16 \\
\hline $40 \mathrm{~min}$ & 16 \\
\hline $25 \mathrm{~min}$ & 15 \\
\hline $5 \mathrm{~min}$ & 9 \\
\hline
\end{tabular}




\section{CON

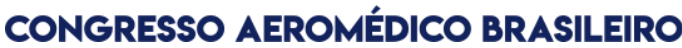

A tabela 2 acima mostra que, em 34 ocorrências, houve RCP por 20 minutos com o serviço aeromédico na cena, o que contribui para o suporte avançado de vida (SAV).

Quanto ao tempo total ofertado com RCP às vítimas, antes e com atuação do SA, totalizamos 34 ocorrências com 30 minutos, como mostra a Tabela 3.

Tabela 3 - Levantamento estatístico de RCP total com a assistência do SA no período de 24 meses, no DF, 2021, em minutos:

\begin{tabular}{|c|c|}
\hline RCP em MINUTOS total & № ocorrências \\
\hline 30 min & 34 casos \\
\hline 50 & 33 \\
\hline 40 & 31 \\
\hline 60 & 22 \\
\hline 45 & 19 \\
\hline
\end{tabular}

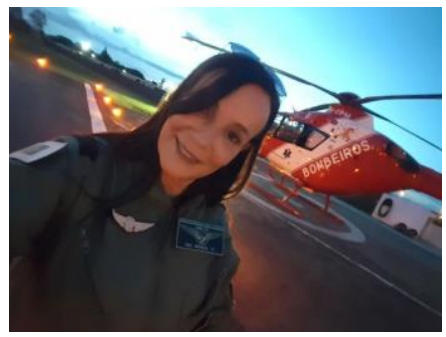

Figura 1:

Arquivo

pessoal.

Salientamos que na busca de fundamentação teórica, não encontramos estudos com informações de RCP antes e depois da chegada do SA na cena.

O estudo revela que dos 1023 atendimentos nos 24 meses, 511 resultaram em óbitos e 487 em não óbitos, sendo ausente menção de óbito ou não óbito em 25 fichas, o que soma 511 (óbitos) + 487 (não óbitos) + 25 (citação ausente) = 1023 .

A maior incidência de ocorrências diagnosticou PCR, somando 425 casos (41,54\%). Desses, 100 (23,53\%) apresentaram RCE e 325 (76,47\%) foram óbitos após RCP. Na literatura se observa que a maioria das PCR extra-hospitalares é de causa presumivelmente cardíaca (CRESPÍ, 2017). Relato de estudo em Osaka, a taxa de admissão hospitalar após RCE foi de 29,2\% e a sobrevivência um mês após a PCR foi de 5,3\%, com resultado neurológico favorável em 1,3\% das vítimas (KITAMURA et al, 2017).

\section{CONCLUSÃO}

No presente estudo o SUAPH DF retrata que as urgências estão em prioridades de atendimento dentro da central de regulação ao despacho do SA.

O acionamento prioritário foi PCR, com Retorno da Circulação Espontânea em $23,53 \%$ dos que receberam RCP, com oferta de SBV e SAV no local da cena com SA, até o transporte à unidade de saúde com regulação na central médica.

Reflexões sobre a integração multiprofissional e interinstitucional, através dos dados estatísticos produzidos, concernem ao planejamento estratégico para capacitação no SA em APH no DF, dentre as quais a RCP, devido ao seu maior quantitativo. Futuras pesquisas serão bem vindas. 


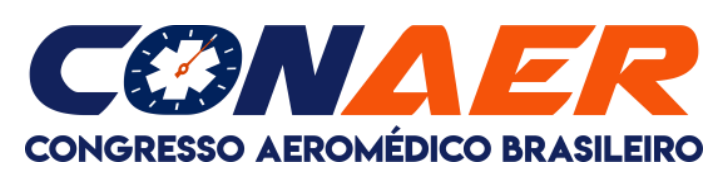

\section{REFERÊNCIAS BIBLIOGRÁFICAS}

AHA (American Heart Association) 2020: LAVONAS, ERIC J; DAVID J. MAGID; KHALID AZIZ, MBBS, BA, MA, MED(IT); KATHERINE M. BERG; ADAM CHENG; AMBER V. HOOVER, RN; MELISSA MAHGOUB; ASHISH R. PANCHAL; AMBER J. RODRIGUEZ; ALEXIS A. TOPJIAN, MSCE; COMILLA SASSON; e a equipe do Projeto de Destaques das Diretrizes da AHA. Editor da versão em português: Hélio Penna Guimarães, FAHA. 2020 American Heart Association JN-1088. Disponível em: $\quad$ https://cpr.heart.org/-/media/cpr-files/cpr-guidelinesfiles/highlights/hghlghts 2020eccquidelines portuguese.pdf Acesso em: 31 ago. 2021.

BENI, E. Resgate Aeromédico. Serviço Aeromédico de Wiltshire divulga estatística dos atendimentos realizados de janeiro a junho de 2020. 5/9/2020. Disponivel em: https://www.resgateaeromedico.com.br/servico-aeromedico-de-wiltshire-divulgaestatistica-dos-atendimentos-realizados-de-janeiro-a-junho-de-

2020/?fbclid=IwAR2w7P8yiJTlej2azLz9gL5nqrkaTnpOtQCaiAwMv7Z9PLlixof a3Fbj yo Acesso em: 20 mai. 2021.

BITENCOURT, M. R.; IORA, P.; DUTRA, A. de C.; BITENCOURT, M. R.; FRANCO, R. do L.; FONTES, C. E. R.; CARVALHO, M. D. de B.; JOINER, A; VISSOCI, J. R. N.; STATON, C.; ANDRADE, L. de. Helicopter Transportation of Brazilian Trauma Patients: A Comparison of Times to Care. Air Medical Journal 00 (2021) 1-5. DOI: https://doi.org/10.1016/j.amj.2021.03.003 journal homepage: http://www.airmedicaljournal.com/ Disponível em: https://www.airmedicaljournal.com/article/S1067-991X(21)00045-6/fulltext Acesso em: 13 jun. 2021.

BRASIL. Ministério da Saúde. Gabinete do Ministro. Portaria no 40 , de 05 de dezembro de 2018. Regulamenta a Portaria Conjunta no que se refere às competências da União, estados e Distrito Federal, na área de Atendimento PréHospitalar. Diário Oficial da União, Brasília, DF, 05 dez. 2018. p. 6. Disponível em: https://www.resgateaeromedico.com.br/wp-content/uploads/2020/04/DODF-

Portaria conjunta-SAMU.pdf Acesso em: 05 jun. 2021.

CRESPÍ. S. L; ROZALÉN, C. MI, ROCA, R. P; CUELLA, M. N; SÁNCHEZ C.A, RIPOLL, V; et al. Características epidemiológicas de las paradas cardiorrespiratórias extra hospitalarias registradas por el sistema de emergências 061 (SAMU) de la Comunidad Autónoma de las Islas Baleares 2009-2012. Med Intensiva [Internet]. 2017 May 19];39(4):199-206. Available from: http://www.medintensiva.org/es/caracteristicas-epidemiologicas-lasparadascardiorrespiratorias/articuloresumen/S0210569114001296/

KITAMURA T, KIYOHARA K, SAKAI T, IWAMI T, NISHIYAMA C, KAJINO K, et al. Epidemiology and outcome of adult out-of-hospital cardiac arrest of non-cardiac origin in Osaka: a population based study. BMJ Open, 2017 Apr 11];4(12):e006462. Available from: https://www.ncbi.nlm.nih.gov/pmc/articles/PMC4275684/pdf/bmjopen2014-006462.pdf 


\section{CONAER

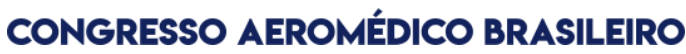

KREUSCH, P. de S. CARACTERÍSTICAS DOS ATENDIMENTOS DE ACIDENTES DE TRANSPORTE TERRESTRE PELO SERVIÇO AEROMÉDICO. Florianópolis, 2018.

https://repositorio.ufsc.br/bitstream/handle/123456789/187144/TCC PRISCILLA KR EUSCH .pdf? sequence=1\&isAllowed=y Acesso em: 13 jun. 2021.

MAIA, P. K. S. Perfil das vítimas atendidas pelo serviço aeromédico do Corpo de Bombeiros Militar do Distrito Federal. 2015. 40 f., il. Monografia (Bacharelado em Enfermagem)—Universidade de Brasília, Ceilândia-DF. 2015. Disponível em: https://bdm.unb.br/bitstream/10483/10899/1/2015 PatriciaKarolineSiqueiraMaia.pdf Acesso em: 18 jun. 2021.

NARDOTO, E. M. L.; DINIZ, J. M. T.; CUNHA, C. E. G.. Perfil da vítima atendida pelo Serviço. Pré-hospitalar Aéreo de Pernambuco. Rev Esc Enferm USP 2011; 45(1): 237-42 www.ee.usp.br/reeusp/ Disponível em: https://www.scielo.br/j/reeusp/a/Frk6FXvwQJjpf4cHvzXyKvN/?lang=pt Acesso em: 13 jun. 2021.

NASCIMENTO, K. C. do; FERNANDES, C. F.; G.IRONDI, J. B. dos R.; SEBOLD, L. F.; HAMMERSCHMIDT, K. S. de A.; MOREIRA, A. R.. Idosos atendidos em um serviço aeromédico. Dez, 2018. DOI: http://dx.doi.org/10.1590/198122562018021.170140 Disponível em: https://www.scielo.br/j/rbgg/a/L8VVcfHW5fZNwqXbzmRj4Wv/?lang=pt\&format=pdf Acesso em: 13 jun. 2021.

PEDREZANI, T. Resgate Aeromédico. Ministério da Saúde habilita helicóptero aeromédico do Corpo de Bombeiro e SAMU 192 DF. 16 abril 2020. Disponível em: https://www.resgateaeromedico.com.br/ministerio-da-saude-habilita-helicopteroaeromedico-do-corpo-de-bombeiros-e-samu-192-do-df// Acesso em: 05 jun. 2021. 